Soc Psychol Personal Sci. 2019 August 1; 10(6): 775-782. doi:10.1177/1948550618792883.

\title{
Who Are the Scrooges? Personality Predictors of Holiday Spending
}

\author{
Sara J. Weston ${ }^{1}$, Joe J. Gladstone ${ }^{2}$, Eileen K. Graham ${ }^{1}$, Daniel K. Mroczek ${ }^{1,3}$, David M. \\ Condon ${ }^{1}$ \\ ${ }^{1}$ Department of Medical Social Sciences, Feinberg School of Medicine, Northwestern University, \\ Chicago, IL, USA \\ ${ }^{2}$ University College London, London, United Kingdom \\ ${ }^{3}$ Department of Psychology, Weinberg College of Arts and Sciences, Northwestern University, \\ Evanston, IL, USA
}

\begin{abstract}
The sharp increase in consumption over the holiday season has important economic implications, yet the psychology underlying this phenomenon has received limited attention. Here, we evaluate the role of individual differences in holiday spending patterns. Using 2 million transactions across 2,133 individuals, we investigate the relationship between the Big 5 personality traits on spending at Christmas. Zero-order correlations suggest holiday spending is associated with conscientiousness, neuroticism, and extraversion; the relationship with neuroticism persists after accounting for possible confounders including income and demographics. These results improve our understanding of how different personality traits predict how people respond to the environmental demands of the holiday season and have broader implications for how personality relates to consumer behavior.
\end{abstract}

\section{Keywords}

consumer psychology; Big 5 personality; spending; holiday season

In most Western countries, the holiday season has evolved from a time devoted to religious celebration and family to one that is associated with materialism, consumerism, and excess (Belk, 2001; Kasser \& Sheldon, 2002). Given the importance of holiday shopping to the broader economy, seasonal increases in holiday spending are widely studied in disciplines such as marketing and economics (Dinner, Van Heerde, \& Neslin, 2014; Waldfogel, 2002).

\footnotetext{
Corresponding Author: Sara J. Weston, Department of Medical Social Sciences, Feinberg School of Medicine, Northwestern University, 633 N. St. Clair Street, Chicago, IL 60611, USA. sara.weston@ northwestern.edu.

Authors' Note

Sara J. Weston and Joe J. Gladstone are contributed equally. A supplemental file containing all analysis code and results, including analyses not presented in this manuscript, can be found at https://osf.io/7j9da.

Declaration of Conflicting Interests

The author(s) declared no potential conflicts of interest with respect to the research, authorship, and/or publication of this article.

Supplemental Material

The supplemental material is available in the online version of the article.
} 
However, the psychological factors underlying changes in spending behavior over this period have received comparatively little attention. This is surprising, as individual differences are likely to shape how people react to holiday-related environmental stressors in terms of their subsequent financial behaviors. For example, the holiday season is often a time of increased stress, and psychological stress reduces self-control (Fedorikhin \& Patrick, 2010), which may lead to excessive spending.

Sociodemographic characteristics, money management skills, and psychological factors such as self-control are known contributors to variance in holiday spending (McNair, Summers, de Bruin, \& Ranyard, 2016). However, empirical studies of consumption behavior have not previously been evaluated in the context of the Big 5 personality framework (cf. Matz, Gladstone, \& Stillwell, 2016). Therefore, our aim is to evaluate the role of individual differences in holiday spending patterns.

There are several reasons to believe that personality traits influence holiday spending behavior. First, traits have been linked to broad range of financial outcomes including employee wages and occupational prestige (Judge, Higgens, Thoresen, \& Barrick, 1999) as well as spending and consumption habits (Matz et al., 2016; Troisi, Christopher, \& Marek, 2006). This suggests that holiday spending may be associated with traits relevant to financial or occupational achievement, such as conscientiousness or openness to experience. However, spending over the holiday season is far more than simply a snapshot of consumption at a given time of year or a reflection of one's disposable income. Holiday spending includes a social component, as most spending over this period involves others, such as gifts for friends and family or attending holiday-themed parties. In other words, holiday spending may be as much a function of socially relevant traits, such as extraversion and agreeableness, as they are achievement-oriented ones.

Furthermore, personality traits may be associated with more than just the aggregate amount spent over this period. Holiday seasons often require additional preparation and planning on the part of spenders. Organized gift givers may prepare lists of recipients and potential gifts ahead of time. (Some may even check such lists twice.) Savvy consumers may look out for holiday deals and savings, and so purchases may be timed strategically. Those who plan ahead can take advantage of early sales, while others rush out to complete their shopping on the eve of their celebrated holiday. The degree of preparation and planning over the holiday season is likely to be associated with individual differences including broad traits as conscientiousness.

The goal of the current study is to provide descriptive insights into which personality characteristics are associated with the greatest spending during the holiday period, which we believe can provide both theoretical and practical insights. Theoretically, identifying the relationships between traits and specific financial behaviors, such as spending habits, points to the potential mechanisms that link traits to behavioral outcomes (e.g., Judge et al., 1999; Roberts, Kuncel, Shiner, Caspi, \& Goldberg, 2007; Solomon \& Jackson, 2014). On a practical level, these insights could be used by companies in predicting the psychological antecedents of customer spending patterns. The findings could also prove useful to 
consumers trying to anticipate and reduce potentially harmful spending behavior, in order to make financial decisions more in line with their long-term preferences.

We employ a research setting that should provide high ecological validity, by aggregating together more than 2 million individual spending transactions from participant's bank accounts. These records of spending are then matched to survey measures of personality for each individual. This approach has significant advantages over most research to date, which has relied on self-reports of spending, which may suffer from well-documented response biases (such as consistency motive, covariation bias, or common-method variance).

Our analyses focused assessing the association between personality traits and holiday spending? We preregistered our expectations on the direction of the associations between holiday spending and personality (https://osf.io/ew4h5). We acknowledge that our predictions were not based directly on prior theory and are exploratory, but we felt it important to state our expectations a priori in the preregistration. Our knowledge of personality research, and prior findings on the associations between personality and other (nonfinancial) behaviors, guided our hypotheses. We expected that higher levels of extraversion would be associated with greater spending, because larger friendship networks are likely to expose extroverts to consumption patterns or social comparisons that lead them to spend more (as suggested by Nyhus \& Webley, 2001). However, given we analyzed relationships among several different personality factors without clear precedents or theoretical predictions about the specific relationships among the factors, we considered this research to be exploratory rather than confirmatory.

\section{Method}

\section{Data Set and Participants}

The data set was collected in collaboration with a UK-based money management app in May 2017. The service provides users with an online dashboard of their money by aggregating transactions across all their different bank accounts. Customer account records provided a daily panel of all debits (outgoing) and credits (incoming) transactions across each of a customers' bank accounts (e.g., checking accounts and credit cards). Customers of the service were sent a survey link by e-mail asking them to take part in the study, with the opportunity to win a tablet computer as a prize. Within the survey, participants consented to match their survey responses with their transaction data for research purposes. In total, 2,133 people completed the personality portion of the study and provided their consent to participate. For 1,875 of those participants, the company provided demographic information on gender and year of birth ( $12 \%$ female, $44 \%$ male, $44 \%$ unknown; $x$ [age $]=37.47$ years, $\mathrm{SD}=11.89$ ). Gender was not measured directly but derived by running first names of account users through a names database, providing gender in just over half of the cases. The data set contained 2.2 million individual transaction records in total, meaning participants completed an average of around 1,270 transactions each over the 12previous research using bank account data that have typically month study period. The sample size was not determined in advance, but rather by the available number of transaction data-linked survey responses. All customer data were fully anonymized before being analyzed in this study, and we received ethical approval for the analysis of the data set (IRB: 13463/001). 
The purpose of the mobile application from which the data set is collected is to provide users with a single dashboard of their financial information, by aggregating outgoing and incoming transactions from multiple bank accounts. For example, if a participant had two checking accounts, one credit card, and one savings account, all with different financial services providers, then data from each of these accounts will be recorded by the application. This pooling of account information represents an advantage over previous research using bank account data that have typically relied on information derived from only a single bank (e.g., Matz et al., 2016).

The data set does not provide a representative sample of the UK population. The sample is likely to suffer from selection bias both in the types of users who will choose to sign-up to the service and by those who responded to the e-mail to provide their survey information. The analysis is at the level of individual participants rather than households. This means there is likely to be noise created by intrahousehold transfers of wealth (e.g., if one partner buys all the Christmas shopping for the household, and the other buys nothing).

\section{Measures}

\section{Holiday Spending}

Holiday spending was calculated by summing debit transactions in November and December (i.e., total amount spent on purchases across 61 days; $M=£ 17,527.43, S D=$ $£ 69,338.78, M d n=£ 8,758.45, \mathrm{IQR}=£ 12,167.73)$. This reflects the way organizations tasked with measuring holiday sales (Shearman \& Smith, 2018). This outcome measure was highly skewed. To allow for model estimation under the assumptions of linear modeling, we $\log$ transformed (base $e$ ) the spending variable. Figure 1 displays the distribution of the original and transformed variables.

\section{Average Spending Prior to Holiday Season}

An important control variable in this study is an individual's average spending across a 2month period. To avoid overlap with the outcome (i.e., spending during the holiday season), we calculated this variable using all transactions prior to November 1. Specifically, for each individual, we summed the total amount spent prior to November 1, then divided by the number of days the participants had been enrolled in the study. This yielded the participant's average daily spending prior to the holiday season. In order to better compare this estimate to the outcome, we multiplied the participant's average daily spending by 61 (i.e., the number of days in November and December). Thus, this estimate of spending can be interpreted as spending during a 2-month period. On average, participants spent $£ 23,028.46$ during a given 2-month period $(S D=£ 36,824.73, M d n=£ 13,727.48, \mathrm{IQR}=£ 15,614.28)$. We followed a similar procedure for income/credits to an account. Here, we created a list of spending categories that we considered to be sources of income (e.g., "salary," "(government) benefits," and used the aggregated transactions in these categories as our measure of total income. We excluded credits to their accounts tagged as "repayments," to avoid transactions such as credit card repayments being counted as income. Participants had an average of $£ 1,751.18$ entering their account during a 2-month period ( $S D=£ 5735.49$, $M d n=£ 156.85, I Q R=£ 1,357.54) .{ }^{1}$ This distinction in the calculation of income versus 
spending explains the wide discrepancy in average income and spending. These estimates of income were also log transformed.

\section{Big 5 Personality}

We used a widely accepted model of personality, the "Big 5" (Goldberg, 1992; McCrae \& John, 1992), and measured these traits with the BFI-10 inventory, an established short scale of this framework (Rammstedt \& John, 2007). With Cronbach's as ranging from .31 to .75, the internal consistencies of scales were found to range from poor to acceptable. We note here that the reliability coefficients for agreeableness $(\alpha=.31)$, conscientiousness $(\alpha=.55)$, and openness $\left(\mathrm{a}^{1 / 4} .32\right)$ were the worst of these $\left(\mathrm{a}^{1 / 4} .65\right.$ and .75 for neuroticism and extraversion, respectively). As Cronbach's a is influenced by the number of items in a scale, so the BFI-10, with only 2 items to cover each personality dimension, is likely to have relatively poor values of a (Kline, 2000; Woods \& Hampson, 2005). We therefore interpret our findings based from these traits with caution, and we encourage readers to do the same. To help correct for the low reliabilities, we construct latent variables for each of the traits and use the estimated scores from the latent variable models in our regression models. ${ }^{2}$ The latent variable model is available in the Online Supplementa1 Material (section 1.2.2).

It is worth noting that apart from having direct effects on spending behaviors, personality traits may also have indirect effects such as through income (see Borghans et al., 2008). This is why we controlled for income and other demographics in our main analyses. For clarity, we also present the correlations without controls.

\section{Data Analysis}

We used R (Version 3.4.2; R Core Team, 2017) and the R package Ime4 (Version 1.1.14; Bates, Maechler, Bolker, \& Walker, 2014) for our analyses. We used a simple linear model to assess the degree to which personality traits are associated with the amount spent during the holiday season. This model includes all personality traits simultaneously and controls for age, gender, income, and average spending in a 2-month period (excluding the holiday season). We then used multilevel models to assess trajectories of spending across the holiday season and to estimate the degree to which these trajectories are associated with personality traits.

\section{Preregistration}

Analyses were preregistered and can be found at https://osf.io/ew4h5. Initially, we had planned to use proportions of spending rather than the raw amounts. Therefore, the choice to $\log$ transform the outcomes was not preregistered, and this decision was made after seeing

\footnotetext{
${ }_{1}$ It should be noted that participants did provide a self-report measure of their income when they first signed up to the money management service. Possible responses were less than $£ 10 \mathrm{~K}, £ 10-20 \mathrm{~K}, £ 20-30 \mathrm{~K}, £ 30-40 \mathrm{~K}, £ 40-50 \mathrm{~K}$, $550-60 \mathrm{~K}, £ 60-70 \mathrm{~K}$, $£ 70-80 \mathrm{~K}$, andmorethan£80K. Werecodedthesetobenumericbasedontaking the value in the middle of the range, and the value 85 for the top category ( $£ 5 \mathrm{~K}, £ 15 \mathrm{~K}, £ 25 \mathrm{~K}$, $335 \mathrm{~K}$, $445 \mathrm{~K}$, £55 K, £65 K, £75 K, and £85 K). The Self-Report Scale was both highly skewed and showed littlerelationshipwiththeobservedcreditforeachparticipant. Specifically, thisvariablewasweaklycorrelated, $r=.06(p<$. 001), withour estimate of a participant's income during an average 2-month period. We acknowledge that neither measure of income is perfect. We chose to use estimates of income based on the transactions reported through the app, as these are free of social desirability bias and share method variance with our outcome of interest.

${ }^{2}$ Results using estimated latent variable scores did not substantially change the results when compared to using sum scores.
} 
the data. If outcomes were not transformed, extraversion was negatively associated with holiday spending and associated with trajectories of spending, such that introverts spent relatively equal across the season and extraverts spent less at the beginning and increased their spending leading up to Christmas. We also did not register the use of our measure of income, which we constructed using the objective transaction data rather than using the selfreported measure. When we use the self-reported income measure instead, the results do not change. We chose to use the objective measure as we believe it to be a more accurate measure of income. The spending variable originally used was simply the sum of all spending transactions; this variable does not account for the fact that for a small number of participants, we did not have the full 12 months of data for them. We therefore used a measure that accounted for this difference (see Method section). Also, in the preregistration, we outlined plans for $\beta$ To provide full transparency regression to estimate participant's proportion of spending. Our attempts to use this model either failed to converge or yielded null results and therefore are not presented here. Additional exploratory analyses include use of the fractional logit, but this also yielded null findings. Finally, we preregistered models assessing changing in spending by day over the 2-month holiday period. We report the results of those analyses here. To provide full transparency in our research approach, all analyses performed — whether confirmatory or exploratory—are documented in Online Supplemental Material 1.

\section{Results}

Person-level summary statistics and correlations are shown in Table 1. Total holiday spending (log-transformed) was positively associated with extraversion $(r=.06,95 \%$ CI [ $02, .10], t(2,131)=2.88, p=.004)$, conscientiousness $(r=.11,95 \%$ CI $[.07, .15], t(2,131)=$ $4.99, p<.001)$ and negatively associated with neuroticism $(r=.11,95 \%$ CI [.16, .07], $t(2,131)=5.30, p<.001)$. Holiday spending was not found to be associated with agreeableness $(r=.02,95 \%$ CI $[.07, .02], t(2,131)=1.05, p=.295)$ or openness $(r=.04$, $95 \%$ CI $[.08, .00], t(2,131)=1.92, p=.055)$.

A single linear model was estimated to assess the relationship of personality traits to holiday spending, controlling for each individual trait, age, gender, income, and average spending in a 2-month period. Results are shown in Table 2. In this model, holiday spending was negatively associated with both neuroticism ("b $=0.06$ ", 95\% CI [0.11, 0.01], " $\mathrm{t}(1925)=$ $2.38 ”, " \mathrm{p}=.017 ”)$ and openness to experience $(b=0.09,95 \% \mathrm{CI}[-0.16,-0.02], t(1925)$ $-2.44, p=.015)$. These effects are illustrated in Figure 2. Conscientiousness was also weakly associated with holiday spending, $b=.05,95 \% \mathrm{CI}[.00, .10], t(1,925)=2.12, p=$. 034. However, given the weak evidentiary value (i.e., the $\mathrm{p}$ value close to .05 and the CI containing 0 ), we do not consider this sufficient statistical evidence for a positive association between conscientiousness and holiday spending after controlling for other traits and demographic variables. Other significant variables in the model included being male, having a higher income, and having a higher total expenditure. A participant's age was not a significant predictor of holiday spending in this model.

Finally, we estimated the trajectory of spending across the holiday period. In this analysis, we looked only at transactions that occurred during the months of November and December. 
We did not find a significant interaction between the personality traits with day of the holiday season in predicting spending. The full results of this model can be seen in the Online Supplemental Material (Table 6). ${ }^{3}$

\section{Discussion}

Taking advantage of a unique data set, the present study found significant relationships between spending amounts over the holiday season and personality. The results indicate that, holding constant financial and demographic covariates, more nervous and stress-reactive participants (higher neuroticism) spent less during the holiday season, as did those with more artistic interests and more active imaginations (higher openness). While these findings were not hypothesized, we can speculate as to why these patterns may have emerged. First, individuals high in openness are typically low in conventionality and traditionalism, and this likely makes them less inclined to conform to societal norms regarding gift-giving (e.g., at holiday gatherings or among others outside of close friends and family). As for neuroticism, the measure of this trait in the current study assessed the extent to which an individual gets nervous easily and handles stress. An individual low on this metric of neuroticism is relatively relaxed and not easily unnerved and may be less inclined to spend money on expensive social events or on purchasing the "perfect" gift for others. In other words, those who are low in neuroticism may be more inclined to spend their money more freely, untethered by the pressure and fear of disappointing others. The zero-order correlations between holiday spending and personality also show a positive association with extraversion (e.g., having a larger social network on which to spend holiday funds) and conscientiousness (e.g., being more organized and proactive regarding holiday events and spending). Further exploratory and confirmatory research is needed to identify the mechanisms underlying these findings, but the results indicate that at least some variance in holiday consumption patterns can be explained by Big 5 personality traits. That said, we did not find evidence for a significant relationship between personality traits and trajectories of holiday spending. In other words, we were not able to distinguish between those who plan their holiday purchases well in advance and those who rush to complete their shopping on December 24.

The effect sizes we report between personality and spending were small. This is perhaps unsurprising, given the wealth of influences that shape spending during the holiday season (e.g., household size, income from multiple sources) as well as our use of brief personality measures and the relatively noisy environment of combining transactions over time to capture spending. While personality may explain only a small amount of variance in holiday spending at an individual level, if we consider these relationships at an aggregated macrolevel, such as a retailer modeling the holiday-spending patterns of millions of customers, the role of personality may still represent an important component of holiday spending (see Matz et al., 2016).

\footnotetext{
${ }^{3}$ Additionally, we provide plots summarizing average spending during the holiday season, both on average and at different levels of personality traits. There are no formal tests of these trajectories or patterns. However, we note that spending tends to increase at the beginning of a week (Monday) and decrease on the weekends. There is an additional bump in spending around December 1. And, perhaps unsurprisingly, the least amount of spending occurs on December 25.
} 
Our findings contribute to understanding how individual differences shape consumer behavior by highlighting potential predispositions, which encourage or inhibit spending. This is important, as excessive consumption remains a major social challenge for modern society (De Graaf, Wann, \& Naylor, 2005). Specifically, the expanding consumer debt burden created by excessive spending poses a risk to countries such as the United Kingdom and United States-where half or more of household's report being unable to fund emergency expenses without seeking high-cost credit (Lusardi et al., 2011). In this context, we believe there is benefit to even small gains in understanding who spends the most and why.

For social and personality psychologists, these results can contribute to a deeper understanding of the associations between individual traits and socially important outcomes. For example, personality traits have been linked with financial success (Judge et al., 1999), but the mechanisms underlying these relationships are largely unclear. Is conscientiousness related to greater net worth (Duckworth, Weir, Tsukayama, \& Kwok, 2012) because of saving habits, higher lifetime earnings, or less impulsive spending? Our results suggest that conscientiousness is not associated with lower spending during the holiday season (and may be associated with spending more), providing indirect evidence that conscientious individuals increased savings is unlikely to be (at least primarily) the result of differences in spending, and more likely to be driven by income mechanisms, such as higher paying jobs. Furthermore, our findings suggest new hypotheses concerning the association between neuroticism and openness with financial success, as these relationships may partially depend upon the degree to which these individuals spend money on others.

A further contribution of this research is in its methods. While previous research approximated spending with selfreported purchase intention or history (Aaker, 1999; Huang et al., 2012; Sirgy, 1985), we extracted spending directly from bank-reported transaction records. In doing so, we were able to overcome some of the limitations of self-report measures and produce results with high external validity. For example, a participant asked to recall historic spending from 12 months ago is likely to suffer from biases in their recall, while using digital records of behavior reduces the potential for these memory biases.

The use of objective measures of spending also has potential limitations. For one, if a user has only connected a subset of their financial accounts to the app, such as by adding only a secondary checking account, then our measures of their spending and income will be underestimated. Self-reports may have provided a more accurate measure of overall spending and income for individuals for whom we are not capturing their full transaction history across their accounts. Furthermore, as our measure of spending includes all money leaving an individual's accounts, this is likely to exaggerate spending in some circumstances. For example, if an individual was to lend money to a friend, knowing they would receive the money back in future, this would be calculated as an expenditure rather than as a debt to be repaid in future. Similarly, transfers across financial products, depending on how these were tagged in the application, were also included in our calculation of expenditure. To limit the overestimation of spending, we explicitly removed repayments to credit products (i.e., credit card repayments), to prevent these transactions being "double- 
counted" as expenditure. Despite these attempts to minimize error, our spending variables should be considered as estimates of spending rather than precise measures.

Our study has several limitations that should be considered when interpreting the findings, which offer possible avenues for future research. Future research should seek to address the primary limitation of the current work by using more granular measures on both spending and personality. The use of more narrow categorizations (e.g. gifts, parties, and charitable donations) of spending, for example, would allow for the evaluation of more fine-grained associations with each of the traits. It remains to be seen whether extroverts are spending more on social outings and whether agreeableness is associated with gift-giving, as these relationships are obscured by aggregating total spending. Similarly, it may be that the current measure of personality is too broadly operationalized to capture variance in trajectories of spending. This should be evaluated by using longer personality measures that allow for more narrow evaluation of the individual facets comprising the Big 5 traits. Stronger relationships between personality and outcomes often emerge when more narrowly defined facets are used (Paunonen \& Ashton 2001). For example, while the broad trait of conscientiousness may not be associated with purchasing gifts early in the holiday season, the facet "organization" (a component of conscientiousness) may be.

In addition to examining the potential impact of personality on holiday spending, our research poses several other intriguing questions that merit follow-on work. Future research might fruitfully parse different motivations for why people spend more during the holiday season. For instance, if some people spend more primarily to appear wealthy to others (i.e., they are motivated by signaling status to others), we could expect this motivation to increase their visible consumption (e.g., clothing, transportation, and housing) and not their private consumption (e.g., groceries and energy bills).

Our research provides preliminary, but encouraging, evidence for an association between personality and spending over the holiday season. While many important questions remain for future investigation, by providing objective measures of both annual and holiday spending, these data allow for a truly ecological study of the relationship between personality traits and consumer behavior.

\section{Supplementary Material}

Refer to Web version on PubMed Central for supplementary material.

\section{Acknowledgments}

Funding

The author(s) disclosed receipt of the following financial support for the research, authorship, and/or publication of this article: This research was supported, in part, by the National Institute on Aging grants P01-AG043362, awarded to Daniel K. Mroczek, Co-Investigator and Project Leader and R01-AG018436, awarded to Daniel K. Mroczek, Principal Investigator. 


\section{Author Biographies}

Sara J. Weston is a postdoctoral fellow in the Medical Social Sciences Department in the Feinberg School of Medicine at Northwestern University. Her research focuses on the role of personality in understanding changes in and reactions to health. She is an open science advocate.

Joe J. Gladstone is an Assistant Professor of Consumer Behaviour at UCL School of Management. His work investigates the psychology of financial decision-making, with a focus on analysing spending records collected from bank accounts.

Eileen K. Graham is a research assistant professor of medical social science at Northwestern University. Her work examines personality development across the adult life span and individual differences in physical and cognitive health in older adulthood.

Daniel K. Mroczek holds a shared appointment at Northwestern University between the Weinberg College of Arts \& Sciences, where he is professor of psychology, and the Feinberg School of Medicine, where he is professor of medical social sciences. His research focuses on life span personality and health, personality development in adulthood, and the ways that personality development intersects with health outcomes and longevity.

David M. Condon is an Assistant Professor in the Medical Social Sciences department of the Feinberg Medical School at Northwestern University. He studies the measurement of individual differences and the structure of personality space. Handling Editor: Simine Vazire

\section{References}

Aaker JL (1999). The malleable self: The role of self-expression in persuasion. Journal of Marketing Research, 36, 45-57.

Bates D, Maechler M, Bolker BM, \& Walker S (2014). Fitting linear mixed-effects models using \{\{\}lme4\{\}\}. Journal Of Statistical Software, 67, 1-48. doi:10.18637/jss.v067.i01

Belk RW (2001). Materialism and you. Journal of Research for Consumers, 1, 291-297.

Borghans L, Meijers H, \& Ter Weel B (2008). The role of noncognitive skills in explaining cognitive test scores. Economic Inquiry, 46, 2-12.

De Graaf J, Wann D, \& Naylor TH (2005). Affluenza: The allconsuming epidemic. Oakland, CA: Berrett-Koehler Publishers.

Dinner IM, Van Heerde HJ, \& Neslin SA (2014). Driving online and offline sales: The cross-channel effects of traditional, online display, and paid search advertising. Journal of Marketing Research, 51, 527-545. doi:10.1509/jmr.11.0466

Duckworth AL, Weir D, Tsukayama E, \& Kwok D (2012). Who does well in life? Conscientious adults excel in both objective and subjective success. Frontiers in Pyschology, 3, 1-8. doi:10.3389/ fpsyg.2012.00356

Fedorikhin A, \& Patrick VM (2010). Positive mood and resistance to temptation: The interfering influence of elevated arousal. Journal of Consumer Research, 37, 698-711. doi:10.1086/655665

Goldberg LR (1992). The development of markers for the big-five factor structure. Psychological Assessment, 4, 26-42. doi:10.1037/1040-3590.4.1.26

Huang H, Mitchell V-W, \& Elliott R (2012). Are consumer and brand personalities the same? Psychology and Marketing, 29, 334-349. doi:10.1002/mar.20525

Judge TA, Higgins CA, Thoresen CJ, \& Barrick MR (1999). The big five personality traits, general mental ability, and career success across the life span. Personnel psychology, 52, 621-652. 
Kasser T, \& Sheldon KM (2002). What makes for a merry christmas? Journal of Happiness Studies, 3, 313-329. doi:10.1023/A:1021516410457

Kline P (2000). Other types of psychological tests In The handbook of psychological testing (pp. 325346). Florence, KY: Taylor \& Francis.

Lusardi A, Schneider DJ, \& Tufano P (2011). Financially fragile households: Evidence and implications (No. w17072). National Bureau of Economic Research.

Matz SC, Gladstone JJ, \& Stillwell D (2016). Money buys happiness whenspendingfitsourpersonality.PsychologicalScience, 27,715-725.

McCrae RR, \& John OP (1992). An introduction to the five-factor model and its applications. Journal of Personality, 60, 175-215. doi:10.1111/j.1467-6494.1992.tb00970.x

McNair S, Summers B, de Bruin WB, \& Ranyard R (2016). Individual-level factors predicting consumer financial behavior at a time of high pressure. Personality and Individual Differences, 99, 211-216. doi:10.1016/j.paid.2016.05.034

National Retail Federation. Holiday FAQs. Retrieved January 6, 2018, from https://nrf.com/resources/ consumer-research-and-data/holiday-spending/holiday-headquarters/holiday-faqs

Nyhus EK, \& Webley P (2001). The role of personality in household saving and borrowing behaviour. European Journal of Personality, 15, S85-S103. doi:10.1002/per.422

Paunonen SV, \& Ashton MC (2001). Big five factors and facets and the prediction of behavior. Journal of Personality and Social Psychology, 81, 524. [PubMed: 11554651]

Rammstedt B, \& John OP (2007). Measuring personality in one minute or less: A 10-item short version of the big five inventory in english and German. Journal of Research in Personality, 41, 203-212. doi:10.1016/j.jrp.2006.02.001

R Core Team. (2017). R: A language and environment for statistical computing Vienna, Austria: R Foundation for Statistical Computing https://www.R-project.org/.

Roberts BW, Kuncel NR, Shiner R, Caspi A, \& Goldberg LR (2007). The power of personality: The comparative validity of personality traits, socioeconomic status, and cognitive ability for predicting important life outcomes. Perspectives on Psychological Science, 2, 313-345. [PubMed: 26151971]

Shearman JC, \& Smith AS (2018, 1 12). Holiday retail sales increased 5.5 percent in 2017, exceeding NRF forecast and showing strongest gain since great recession. National Retail Federation. Retrieved from https://nrf.com/media/press-releases/holiday-retailsales-increased-55percent-2017-exceeding-nrf-forecast-and

Sirgy MJ (1985). Using self-congruity and ideal congruity to predict purchase motivation. Journal of Business Research, 13, 195-206.

Solomon BC, \& Jackson JJ (2014). The long reach of one's spouse: Spouses' personality influences occupational success. Psychological Science, 25, 2189-2198. [PubMed: 25326507]

Troisi JD, Christopher AN, \& Marek P (2006). Materialism and money spending disposition as predictors of economic and personality variables. North American Journal of Psychology, 8, 421436.

Waldfogel J (2002). Gifts, cash, and stigma. Economic Inquiry, 40, 415-427. doi:10.1093/ei/40.3.415

Woods SA, \& Hampson SE (2005). Measuring the big five with single items using a bipolar response scale. European Journal of Personality. doi:10.1002/per.542 


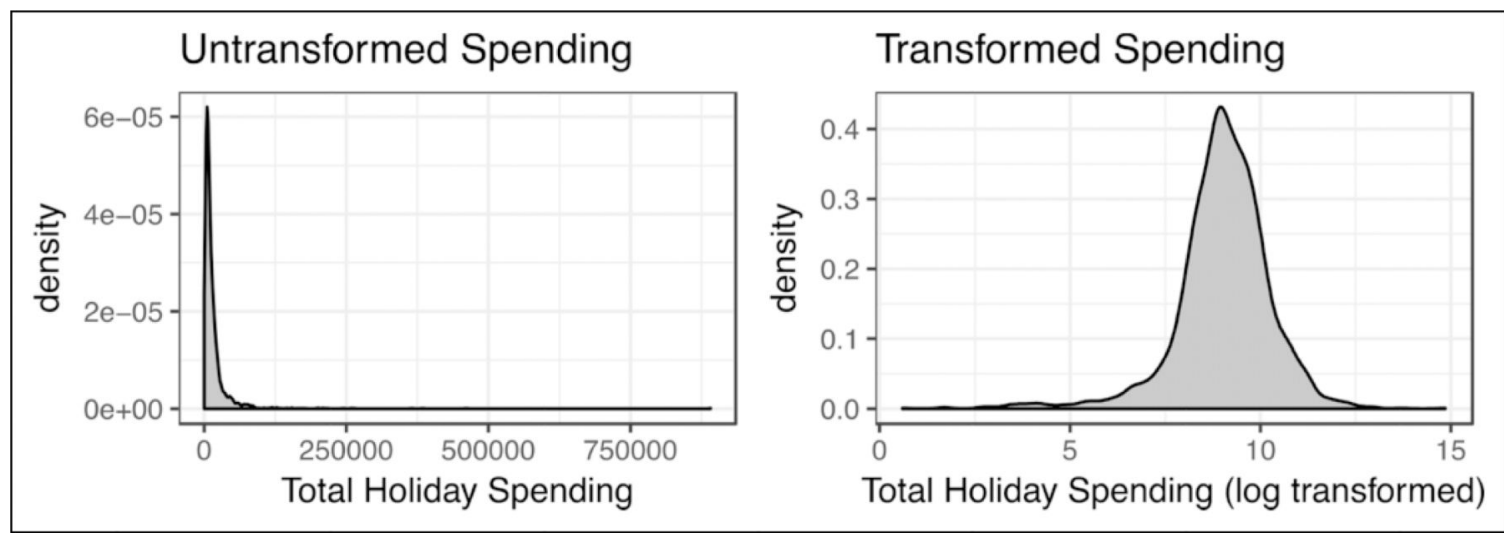

Figure 1.

Distributions of original and log-transformed holiday spending. Due to the extreme skew of the original variables, total spending is censored in this plot at 1,000,000. 


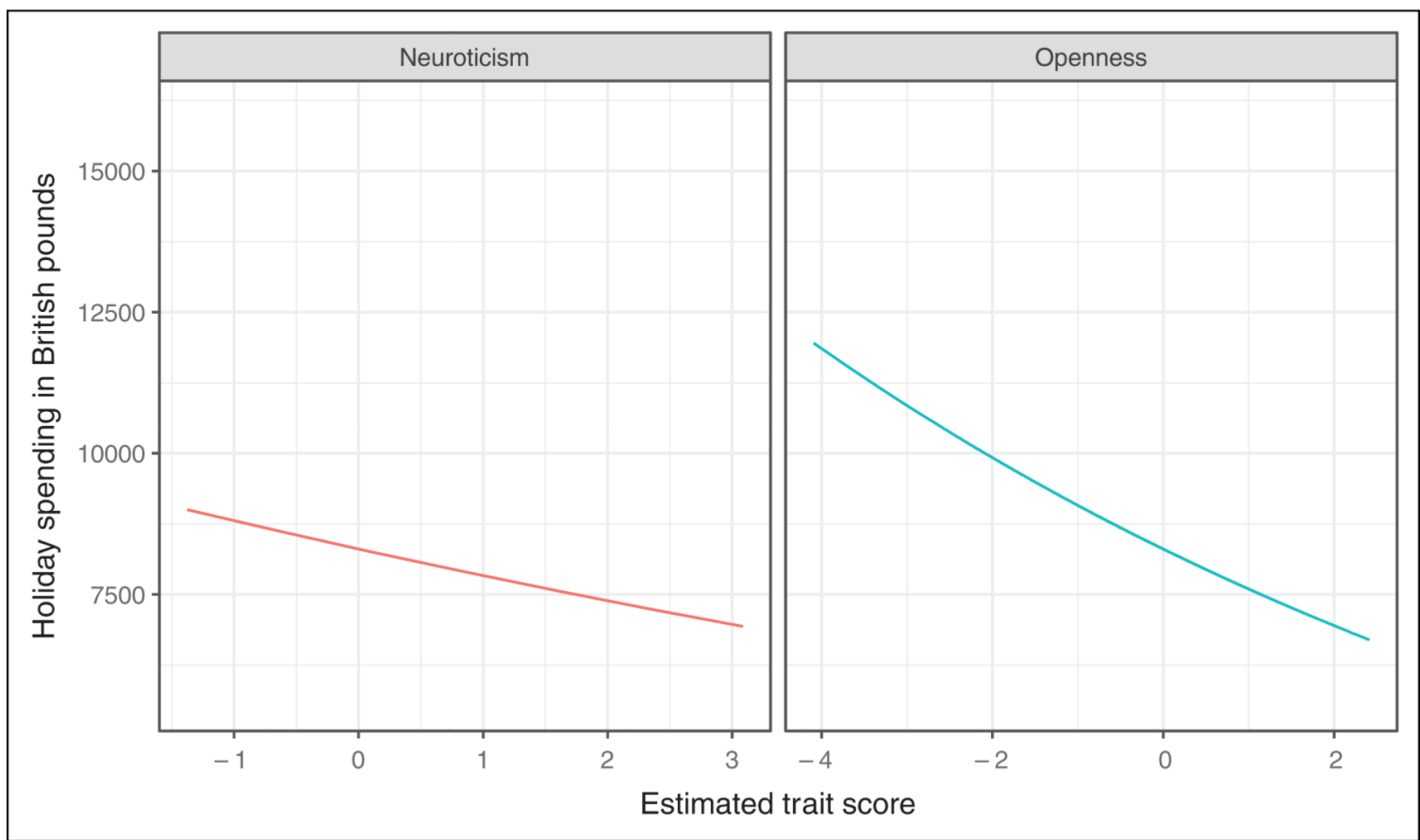

Figure 2.

Predicted holiday spending by neuroticism and openness to experience. Estimates control for age, gender, estimated income, estimated spending, and the other Big 5 personality traits. Shaded areas represent the $95 \%$ confidence bands. 

Table 2.

Linear Model Estimating the Relationship of Holiday Spending (Log Transformed) to Personality Traits.

\begin{tabular}{lcccc}
\hline Predictor & $\boldsymbol{b}$ & $\mathbf{9 5 \%} \mathbf{C I}$ & $\boldsymbol{t}(\mathbf{1 , 9 2 5})$ & $\boldsymbol{p}$ \\
\hline Intercept & 1.73 & {$[1.29,2.17]$} & 7.75 & $<.001$ \\
Age & 0.01 & {$[-0.04,0.05]$} & -0.24 & .808 \\
Male & 0.12 & {$[0.03,0.21]$} & 2.63 & .009 \\
Income & 0.05 & {$[0.04,0.07]$} & 7.43 & $<.001$ \\
Spend & 0.73 & {$[0.69,0.78]$} & 30.41 & $<.001$ \\
Extraversion & 0.04 & {$[-0.02,0.11]$} & 1.25 & .211 \\
Agreeableness & -0.03 & {$[-0.08,0.02]$} & -1.31 & .190 \\
Conscientiousness & 0.05 & {$[0.00,0.10]$} & 2.12 & .034 \\
Neuroticism & -0.06 & {$[-0.11,-0.01]$} & -2.38 & .017 \\
Openness & -0.09 & {$[-0.16,-0.02]$} & -2.44 & .015 \\
\hline
\end{tabular}

Note. Estimates of income and spending are log transformed. Age is standardized. Personality traits are the estimated scores from a latent variable trait model. Male is a binary variable indicating whether the participant's selfreported gender is male. 